\title{
Superparamagnetic Particle Size Limit of Mn-Zn Ferrite Nanoparticles Synthesised Through Aqueous Method
}

\author{
R. Justin Joseyphus ${ }^{1,2}$, A. Narayanasamy ${ }^{2}$, B. Jeyadevan ${ }^{1}$, K. Shinoda ${ }^{1}$ and K. \\ Tohji ${ }^{1}$
}

${ }^{1}$ Graduate School of Environmental Studies, Tohoku University, AramakiAza Aoba-ku, Sendai 980-8579, Japan.

${ }^{2}$ Materials Science Centre, Dept. of Nuclear Physics, University of Madras, Guindy Campus, Chennai-25, India.

\begin{abstract}
Mn}_{0.67} \mathrm{Zn}_{0.33} \mathrm{Fe}_{2} \mathrm{O}_{4}$ nanoparticles with size ranging from 20 to $80 \mathrm{~nm}$ have been synthesized using the modified oxidation method. The Curie temperatures for all the samples are found to be within $630 \pm 5 \mathrm{~K}$ suggesting that there is no size-dependent cation distribution. Mössbauer studies on the synthesized nanoparticles suggest that the critical particle size limit for superparamagnetism to be about $25 \mathrm{~nm}$ at $293 \mathrm{~K}$.
\end{abstract}

Keywords: Oxidation method; Mn-Zn ferrite; Mössbauer spectroscopy; magnetic properties.

PACS: $74.25 . \mathrm{Ha} ; 75.50 . \mathrm{Gg} ;$ 75.50.Tt; 76.80.+y

\section{INTRODUCTION}

Ferrite nanoparticles find important applications in heat transfer devices, drug delivery systems and in medical diagnostics [1-3]. A prior knowledge of the magnetic properties of nanoparticles is important to decide upon the type of application for the ferrites. For example superparamagnetic nanoparticles are used for biomedical applications like magnetic fluid hyperthermia and ferro/ferrimagnetic nanoparticles are used in high frequency applications. The determination of critical superparamagnetic particle size limit in magnetic nanoparticles is essential to utilize the nanoparticles for specific applications. The critical size for superparamagnetism has also been calculated for various ferrites with the sizes being $14 \mathrm{~nm}, 25 \mathrm{~nm}$ and $50 \mathrm{~nm}$ for the $\mathrm{CoFe}_{2} \mathrm{O}_{4}, \mathrm{Fe}_{3} \mathrm{O}_{4}$ and $\mathrm{MnFe}_{2} \mathrm{O}_{4}$ respectively [4]. The coprecipitation technique has been used in the synthesis of $\mathrm{CdFe}_{2} \mathrm{O}_{4}$ [5], $\mathrm{ZnFe}_{2} \mathrm{O}_{4}$ [6], $\mathrm{Ni}-\mathrm{ZnFe}_{2} \mathrm{O}_{4}$ [7] and $\mathrm{MgFe}_{2} \mathrm{O}_{4}$ [8] in addition to other spinel ferrites. The size-dependent magnetic properties of $\mathrm{MnFe}_{2} \mathrm{O}_{4}$ with particle size from 5 to 25 $\mathrm{nm}$ have been studied for the samples synthesized using the coprecipitation method [9]. The superparamagnetic behaviour of $\mathrm{CuFe}_{2} \mathrm{O}_{4}$ has been studied for the coprecipitated samples prepared in a polymer matrix [10]. The superparamagnetic behaviour in $\mathrm{MgFe}_{2} \mathrm{O}_{4}$ in the particle size ranging from $6 \mathrm{~nm}$ to $18 \mathrm{~nm}$ has been studied by Chen and Zhang
[11]. However, it has been found to be difficult to determine the critical particle size limit for superparamagnetism in $\mathrm{Mn}-\mathrm{Zn}$ ferrite nanoparticles without annealing as the particle sizes synthesized through aqueous methods are found to be less than 20 $\mathrm{nm}$ [12]. A modified oxidation method has been used by the authors to synthesise particles with varying sizes without the necessity for annealing. In this paper, we report the critical particle size limit for superparamagnetism of the as-prepared $\mathrm{Mn}-\mathrm{Zn}$ ferrite nanoparticles synthesized through a modified oxidation method.

\section{RESULTS AND DISCUSSIONS}

$\mathrm{Mn}_{0.67} \mathrm{Zn}_{0.33} \mathrm{Fe}_{2} \mathrm{O}_{4}$ was synthesized using analytical grade reagents of $\mathrm{FeSO}_{4} .7 \mathrm{H}_{2} \mathrm{O}, \mathrm{MnCl}_{2} .4 \mathrm{H}_{2} \mathrm{O}$, $\mathrm{ZnSO}_{4} \cdot \mathrm{H}_{2} \mathrm{O}$ and $\mathrm{Fe}_{2}\left(\mathrm{SO}_{4}\right)_{3}$ salts, wherever necessary, fixing the ratio of $\mathrm{Mn}$ to $\mathrm{Zn}$ as 2 . $\mathrm{NaOH}$ was used for the metal hydroxide precipitation and $\mathrm{KNO}_{3}$ was used to oxidize the ferrous ions to the ferric state. The $\mathrm{Fe}$, $\mathrm{Mn}$ and $\mathrm{Zn}$ salts were dissolved separately in water $(250 \mathrm{~mL})$ and $\mathrm{NaOH}$ was also dissolved in an equal amount of water. The details of the experimental procedure and the particle size dependent saturation magnetization values were reported elsewhere [13, 14]. The average particle size was examined using a Hitachi scanning electron microscope (SEM) and also a Hitachi transmission electron microscope (TEM). 
The magnetic properties were studied using a Tamakawa VSM in a maximum applied field of $1 \mathrm{~T}$. The Mössbauer spectra were recorded using a Wiessel constant acceleration Mössbauer spectrometer with a ${ }^{57} \mathrm{Co} / \mathrm{Rh}$ source kept at $293 \mathrm{~K}$. We shall confine our discussions only to the ferrite nanoparticles with average particle size of $80,50,25$ and $20 \mathrm{~nm}$ synthesized using $0.09 \mathrm{M}, 0.15 \mathrm{M}$ and $0.20 \mathrm{M}$ of $\mathrm{KNO}_{3}$ and $35 \%$ ferric ions designated as sample A, $\mathrm{B}, \mathrm{C}$ and $\mathrm{D}$ respectively.

\section{Particle Size Effects on the Curie Temperature}

Figure 1 shows the temperature dependent magnetization in a field of $800 \mathrm{kA} / \mathrm{m}$ for the samples $\mathrm{A}, \mathrm{C}$ and $\mathrm{D}$. These samples show close lying values of $632 \pm 5 \mathrm{~K}, 627 \pm 5 \mathrm{~K}$ and $634 \pm 5 \mathrm{~K}$ respectively for their Curie temperature $T_{c}$, suggesting that there is no significant variation in the composition and also no size-dependent cation distribution. Similar results have been obtained by Jeyadevan et al. [15] in the case of $\mathrm{Mn}-\mathrm{Zn}$ ferrite where the Curie temperature does not change with the particle size. The bulk $\mathrm{Mn}_{0.65} \mathrm{Zn}_{0.35} \mathrm{Fe}_{2} \mathrm{O}_{4}$ shows a Curie temperature of $463 \mathrm{~K}$ [16] whereas the Curie temperature of the nanoparticles of this ferrite is found to be as high as $723 \mathrm{~K}$, which is attributed to the redistribution of the cations among the two sites [17]. The cations $\mathrm{Fe}^{3+}$, $\mathrm{Mn}^{2+}$ and $\mathrm{Zn}^{2+}$ have zero crystal field stabilization energy and hence they can occupy either tetrahedral or octahedral sites randomly. Hence the cation distribution could vary with the method of synthesis $[18,19]$, which explains the observed differences in the values of $T_{c}$ reported in the literature $[17,20]$.

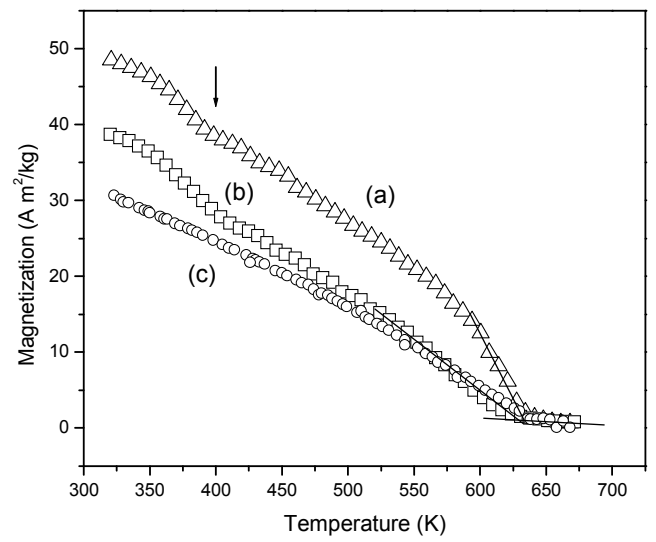

FIGURE 1. The temperature dependent magnetization of the (a) sample A, (b) sample C and (c) sample D in an applied magnetic field of $800 \mathrm{kA} / \mathrm{m}$ [Ref. 14].

\section{Metastable Cation Distribution}

The heating during thermomagnetic measurements can facilitate cation redistribution and hence the metastable cation distribution in the as synthesized particles starts transforming to a thermally induced stable distribution as could be easily visualized from the change in the shape of the thermomagnetization curve (a) indicated by the arrow as in Figure 1. The redistribution of cations has resulted in an increase in $T_{c}$ as could be visualized from the figure. The thermomagnetic measurements were also performed in a thermogravimetric analyzer (TGA) using a small horse shoe magnet with a field strength of $4 \mathrm{mT}$. Figure 2. (a) shows the change in the weight due to magnetization of the sample $A$ as a function of temperature in the TGA experiment and (b) shows the second run for the same sample. The Curie temperature is found to be $634 \mathrm{~K}$ for the sample A. A broad hump is seen for the sample $\mathrm{A}$ at $520 \mathrm{~K}$ in the virgin condition whereas the hump disappears when the sample is rerun in the TGA experiment. The small increase in the weight of the sample up to $520 \mathrm{~K}$ during the first run is likely to be due to the possible increase in the magnetization because of the change in the cation distribution during heating. The disappearance of the hump in the second run suggests that the cation distribution had changed from the metastable state to the equilibrium state on heating during the first run. The above studies suggest that, in the nanocrystalline form, the cation distribution is in the metastable state whereas heating the sample takes it to the stable state. The metastable cation distribution is also exhibited by $\mathrm{Mn}-\mathrm{Zn}$ ferrites synthesized through hydrothermal methods [17].

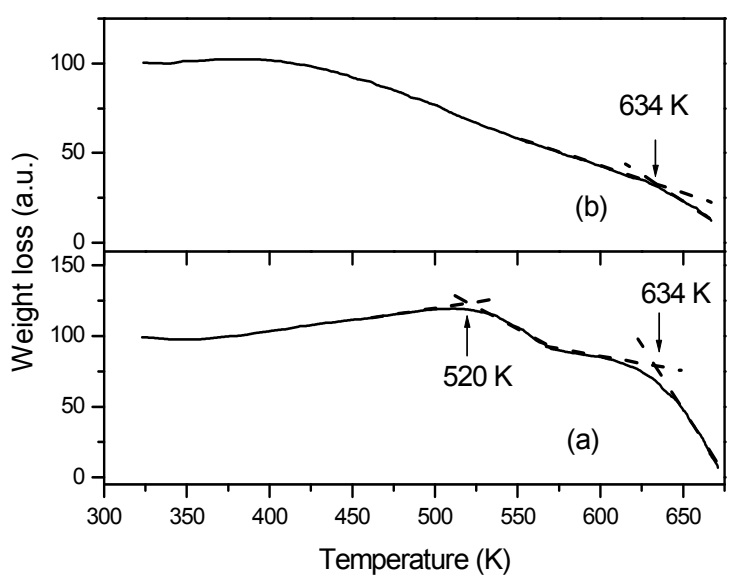

FIGURE 2. (a) The temperature dependence of magnetization of sample A measured in a TGA and (b) second run for the same sample. 


\section{Superparamagnetic Particle Size Limit}

Figures 3.(a)-(d) show the Mössbauer spectra at $293 \mathrm{~K}$ of samples A, B, C and D respectively. Some of the particles in sample A, B and C are magnetically ordered as seen from the appearance of two sextets corresponding to the A- and B- sites of the spinel structure whereas all the particles in sample D are superparamagnetic at $293 \mathrm{~K}$. The percentage volume of the magnetically ordered particles in samples A and $\mathrm{B}$, as observed from the relative area of the sextet, is $81-82 \%$ which decreases to $52 \%$ for sample $\mathrm{C}$ and to $0 \%$ for sample D. The superparamagnetic doublet in sample D indicates that the blocking temperature of all the particles is below $293 \mathrm{~K}$. It has been reported in the literature [21] that the superparamagnetic limit for the $\mathrm{Mn}-\mathrm{Zn}$ ferrite particles is $20 \mathrm{~nm}$. The coexistence of a sextet for the sample $\mathrm{C}$ with an average particle diameter of $25 \mathrm{~nm}$ (figure 4) and the observation of only a doublet for the sample D with an average particle diameter of $20 \mathrm{~nm}$ suggest that the superparamagnetic limit is around $25 \mathrm{~nm}$ in close agreement with the literature. The appearance of a broad sextet and a doublet for sample $\mathrm{C}$ indicates that the blocking temperature of the particles lies near 293 $\mathrm{K}$. The hyperfine fields for the A- and B- sites are

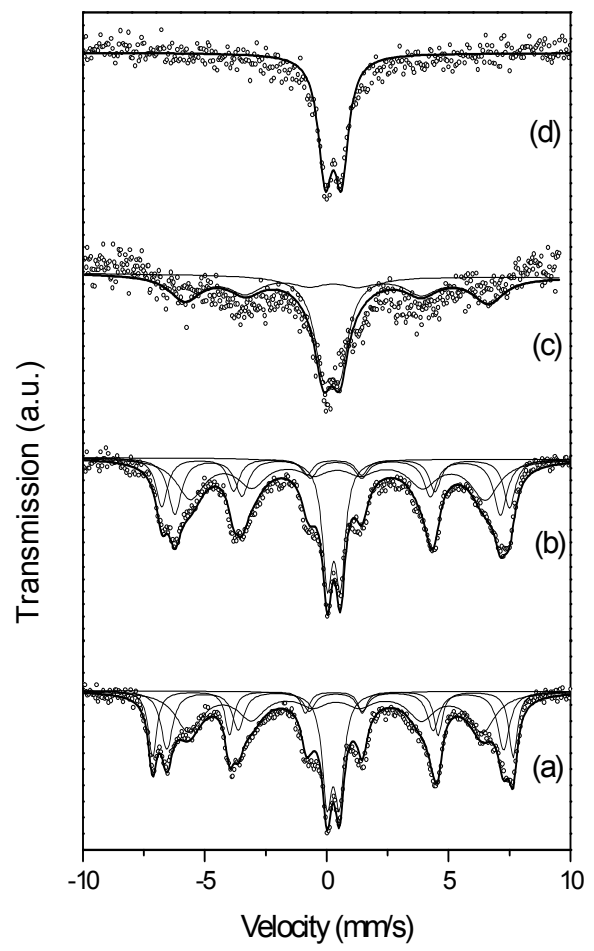

FIGURE 3. The Mössbauer spectrum at $293 \mathrm{~K}$ for (a) sample A, (b) sample B, (c) sample C and (d) sample D [Ref. 14].

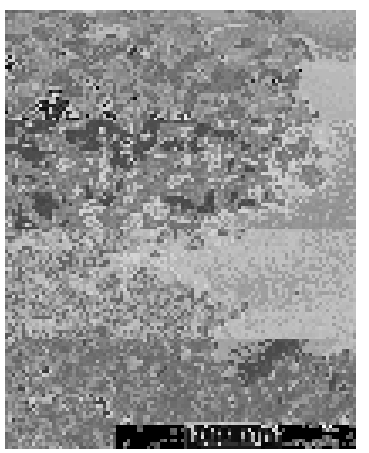

FIGURE 4. The TEM micrograph of sample D

distinctly seen for the samples A and B as shown by the splitting of the sextets. The largest hyperfine field with a smaller isomer shift is characteristic of $\mathrm{Fe}^{3+}$ ions in tetrahedral A- site, whereas the other two sextets with relatively larger isomer shifts represent $\mathrm{Fe}^{3+}$ ions at two different environments in B- site. The A- site isomer shift is expected to be smaller than the B- site isomer shift due to a higher degree of covalency at A- site [22]. For sample C, because of the relaxation effects, the A- and B- site sextets are not distinctly seen and hence the Mössbauer spectrum of this sample is fitted with an average hyperfine field of $38.6 \mathrm{~T}$ and a superparamagnetic doublet. The Mössbauer studies clearly established that the particles are completely superparamagnetic with particle sizes of $20 \mathrm{~nm}$ and it is magnetically ordered for particle sizes above $25 \mathrm{~nm}$ whereas relaxation effect dominates in the vicinity of the critical superparamagnetic particle size region.

\section{CONCLUSIONS}

$\mathrm{Mn}_{0.67} \mathrm{Zn}_{0.33} \mathrm{Fe}_{2} \mathrm{O}_{4}$ nanoparticles with size ranging from 20 to $80 \mathrm{~nm}$ have been synthesized using the modified oxidation method. The Curie temperatures for all the samples are found to be within $630 \pm 5 \mathrm{~K}$ suggesting that there is no size-dependent cation distribution. The critical particle size limit for superparamagnetism is found to be $25 \mathrm{~nm}$ at $293 \mathrm{~K}$. The modified oxidation method can be used to synthesise ferrite nanoparticles of the required size range with specific magnetic properties suitable for applications.

\section{ACKNOWLEDGMENTS}

One of the authors (RJJ) acknowledges the financial assistance from $21^{\text {st }}$ Century $\mathrm{COE}$ Programme on Water Dynamics, Tohoku University. 


\section{REFERENCES}

1. Q. A. Pankhrust, J. Connolly, S. K. Jones and J. Dobson, J. Phys. D: Appl. Phys. 36, R167 (2003).

2. P. Tartaj, M. P. Morales, S. Veintemillas-Verdaguer, T. González-Carreño and C. J. Serna, J. Phys. D: Appl. Phys. 36, R182 (2003).

3. S. Mornet, S. Vasseur, F. Grasset and E. Duguet, $J$. Mater. Chem. 14, 2161 (2004).

4. T. Sato, T. Ijima, M. Seki and N. Inagaki, J. Magn. Magn. Mater. 65, (1987) 252.

5. M. Yokoyama, T. Sato, E. Ohta and T. Sato, J. Appl Phys. 80, 1015 (1996).

6. B. Jeyadevan, K. Tohji and K. Nakatsuka, J. Appl. Phys. 76, 6325 (1994).

7. C. J. Chen, K. Bridger, S. R. Winzer and V.PaiVerneker, J. Appl. Phys. 63, 3786 (1988).

8. Q. Chen, A. J. Rondinone, B. C. Chakoumakos and Z. J. Zhang, J. Magn. Magn. Mater. 194, 1 (1999).

9. Z. X. Tang, C. M. Sorensen, K. J. Klabunde and G. C. Hadjipanayis, J. Appl. Phys. 69, 5279 (1991).

10. S. Roy and J. Ghose, J. Appl. Phys. 87, 6226 (2000).

11. Q. Chen and Z. J. Zhang, Appl. Phys. Lett. 73, 3156 (1998).

12. K. Nishimura, M. Abe and M. Inoue, IEEE Trans. Magn. 38, 3222 (2002).
13. R. Justin Joseyphus, C. N. Chinnasamy, B. Jeyadevan, A. Kasuya, K. Shinoda, A. Narayanasamy and K. Tohji, Proccedings, $1^{\text {st }}$ Intl. Workshop on Water Dynamics, Tohoku University, Japan, 51-53, March 2004.

14. R. Justin Joseyphus, A. Narayanasamy, K. Shinoda, B. Jeyadevan and K. Tohji, J. Phys.Chem. Solids (communicated).

15. B. Jeyadevan, C. N. Chinnasamy, K. Shinoda, K. Tohji and H. Oka, J. Appl. Phys. 93, 8450 (2003).

16. J. Smith and H. P. J. Wijn, in Ferrites, New York: John Wiley, 1959, p. 369.

17. C. Rath, S. Anand, R. P. Das, K. K. Sahu, S. D. Kulkarni, S. K. Date and N. C. Mishra, J. Appl. Phys. 91, 2211 (2002).

18. B. Jeyadevan, K. Tohji, K. Nakatsuka and A. Narayanasamy, J. Magn. Magn. Mater. 217, 99 (2000).

19. S. Son, R. Swaminathan and M. E. McHenry, J. Appl. Phys. 93, 7495 (2003).

20. K. Tkácová, V. Šepelák, N. Števulová, and V. V. Boldyrev, J. Solid State Chem. 123, 100 (1996).

21. K. Mandal, S. Chakraverty, S. Pal Mandal, P. Agudo, M. Pal and D. Chankravorty, J. Appl. Phys. 92, 501 (2002).

22. N. N. Greenwood and T. C. Gibb, in Mössbauer Spectroscopy, London: Chapman and Hall, 1971, Sec. 10. 